\title{
HANS JONAS Y LA RESPONSABILIDAD TECNOLÓGICA
}

\author{
Hans Jonas and Technological Responsibility
}

\author{
Manuel Arboccó de los Heros \\ Universidad Femenina Sagrado Corazón, Perú \\ https://orcid.org/0000-0002-8481-310X \\ marboccod@unife.edu.pe \\ Mag. Jessica Ross Audureau \\ Universidad Femenina del Sagrado Corazón, Perú \\ https://orcid.org/0000-0002-2876-303X \\ jessica.rossa@unife.pe
}

\section{RESUMEN}

El siguiente artículo desarrolla el concepto de responsabilidad tecnológica que estudiara, entre otros pensadores, el filósofo Hans Jonas. Advertidos como estamos, desde hace varias décadas ya, de los peligros hacia a la vida humana, y la vida en general -y hacia el mismo planeta en su totalidad- es que sorprende no encontrar eficientes y extensas políticas institucionales para asumir responsablemente nuestra producción y consumo tecnológico; además de ver la poca conciencia individual ante estos problemas bioéticos. Este trabajo incluye, además, una serie de entrevistas que fueron analizadas y comentadas por los autores. Esperamos que invite a la reflexión, suscite nuevas ideas, y que la responsabilidad tecnológica consiga posicionarse como un valor principal en las sociedades actuales.

\section{Palabras clave:}

Responsabilidad tecnológica, bioética, ambiente, conducta moral, ecosistema

\begin{abstract}
The following article develops the concept of technological responsibility, which was studied, among other thinkers, by the philosopher Hans Jonas. Warned as we have been, for several decades now, of the dangers to human life and life in general -and to the same planet as a whole- it is surprising not to find efficient and extensive institutional policies to take responsibility for our production and technological consumption; in addition to the little individual awareness of these bioethical problems. This work also includes a series of interviews that were analyzed and commented on by the authors. We hope that this will invite reflection, the development of new ideas, and that technological responsibility will be able to position itself as a major value in today's societies.
\end{abstract}

\section{Keywords:}

Technological responsibility, bioethics, environment, moral behavior, ecosystem. 


\section{INTRODUCCIÓN}

La superpoblación, la venta masiva de armas, el narcotráfico y el daño al ecosistema son solo cuatro de los grandes problemas que atraviesa la humanidad desde mediados del siglo XX. Algunos dicen que son problemas irreversibles, que son causas pérdidas; aunque desde hace poco menos de tres décadas hay una mayor consciencia del maltrato al planeta. Un planeta contaminado, recalentado e intoxicado que de seguir así será inviable. De hecho, en algunos lugares ya es muy difícil vivir, por ejemplo, lugares con enorme nivel de contaminación con gases de efecto invernadero (como Japón).

Ecosistemas dañados por inmorales intereses económicos y políticos que, de espaldas a una ética ambiental, atropellan contra todo pronóstico y sentido común, reservas, lagos y bosques. Vemos contaminación de ríos; derrames de petróleo; tala indiscriminada; flora y fauna perjudicada y una desquiciada y poco profesional explotación minera van produciendo un impacto terrible en el mundo en que vivimos. Hablamos de hechos que ocurren en nuestro propio país como en países de todo el orbe. Y es acá donde entra la ética y en especial la bioética.

Como sabemos, la Ética es el campo de la reflexión inteligente y serena sobre asuntos morales, intenta precisar qué es bueno y qué no lo es y por consecuencia cómo podríamos actuar en función a esas consideraciones y ha sido considerada como el "arte de vivir bien" según el filósofo español Fernando Savater. Ahora, la bioética es la rama de la ética que se dedica a proveer los principios para la conducta correcta del humano respecto a la vida, tanto de la vida humana como de la vida no humana, así como al ambiente en el que pueden darse condiciones aceptables para la vida. La bioética es una reflexión ética sobre múltiples problemas sociales y morales propios de la sociedad contemporánea que considera el hábitat que nos brinda vida.

El hombre antiguo y medieval consideraba la naturaleza permanente y en constante cambio, capaz de curarse las pequeñas heridas que el hombre con su minúsculo tamaño podía hacerle (Sánchez Pascual, 1994; prólogo a la obra de Jonas, 1995). Pero con el auge de la tecnología moderna, Hans Jonas señala que ya es necesario hablar de una Ética de la responsabilidad pues el poder destructor del hombre hoy es gigantesco.

Ya existen peligros que amenazan a la humanidad en el plano de su permanencia, de su supervivencia. Son emblemáticas las malas decisiones que afectan el ecosistema, dentro del cual se desarrollan las actividades humanas, o los que resultan de la manipulación biológica aplicada a la reproducción humana, o a la identidad genética de la especie humana, o todavía a la intervención química o quirúrgica sobre el comportamiento del hombre. En suma, debido a la técnica, el hombre se volvió peligroso para el hombre, en la medida que pone en peligro los grandes equilibrios cósmicos y biológicos que constituyen los cimientos vitales de la humanidad (de Siqueira, 2001).

Los daños observables que se presentan movilizan en las personas los sentimientos de angustia y sufrimiento. Para el profesor de bioética de Siqueira (2001) las consideraciones éticas no se imponen como coerción, sino como una fuerte exhortación dirigida a la libertad del agente de transformación. Y es justamente como una exhortación singular que la responsabilidad ética 
se convierte en sentimiento y es en ese campo del comportamiento que Hans Jonas pretende colaborar. Todos, aunque de modo superficial, conocen los posibles cataclismos que ocurrirán como consecuencia del supercalentamiento del planeta, o de la progresiva destrucción de la capa de ozono, o aun, de la incontrolable destrucción de la vegetación de las ya escasas reservas forestales del planeta, el proyecto del genoma humano o el empleo de biochips para el control laboral. Como afirma Gonzáles: "la promesa de la técnica moderna de crearnos un mundo feliz a través del dominio, sometimiento y uso de la naturaleza se ha convertido más bien en una amenaza" (2015, p. 7).

A pesar del mal ya realizado al planeta, hoy pareciera haber una mayor sensibilización de la población cuando de respetar y cuidar nuestro hábitat se trata. Esto le pertenece también a la bioética, como ya se ha dicho, junto con otros temas controversiales como la eutanasia y el aborto; así como la atención de calidad en materia de salud, el respeto al paciente en la atención médica y psicológica; el cuidado de los recursos naturales y debates en temas de investigación comportamental y genética. Así pues, si bien la bioética es relativamente recientedesde lo académico-, tiene gran relevancia dentro de las reflexiones universitarias y académicas en asuntos morales. Ojalá también los políticos y empresarios, que son los que toman las grandes decisiones, la tengan bien presente.

Este trabajo que aquí presentamos tiene como punta de lanza la propuesta del filósofo alemán Hans Jonas (1903-1993) cuyo nombre se asocia al llamado Principio de la Responsabilidad, una propuesta ética para el mundo moderno cuyo avance tecnológico avanza en desmedro del bienestar del ecosistema. A continuación, una breve introducción al principio de la responsabilidad tecnológica de Hans Jonas y un análisis psico-socio axiológico a partir de ocho entrevistas realizadas a un grupo de personas adultas de Lima Metropolitana durante los meses de mayo y junio del año 2020. Debemos también señalar que los autores contaron con las observaciones y amables sugerencias del profesor Ángel Gómez Navarro durante el curso Psicología Axiológica del Doctorado en Psicología desarrollado en la UNIFÉ.

\section{MARCO CONCEPTUAL}

Para Lezama (2007) los riesgos asociados a las llamadas tecnociencias se han acentuado por el nihilismo imperante en las sociedades contemporáneas, debido en gran parte a la desaparición de los valores y sentidos tradicionales (religión, metafísica...) que señalaban límites absolutos e infranqueables. Yseguidamente afirma que, como consecuencia de ello, la ciencia moderna ha vaciado el mundo de sentido y cosificado a los seres vivos. El filósofo español Fernando Savater en su libro Las preguntas de la vida señala que:

Las sociedades modernas de masas tienden a despersonalizar las relaciones humanas, haciéndolas apresuradas y burocráticas, es decir muy "frías" si se las compara con la "calidez" inmediata de las antiguas comunidades, menos reguladas, menos populosas y más homogéneas" (Savater, 2007, p. 195).

La promesa de una técnica moderna se ha convertido en una amenaza para la cual la ética conocida no alcanza, por eso la propuesta de Jonas. La ética de la responsabilidad, para Lezama, debe rebasar el antropocentrismo en el que descansan los modelos éticos tradicionales en razón del nuevo tema de 
la responsabilidad asumida en el contexto del desarrollo tecnológico moderno (Lezama, 2007). La idea es pasar así, de un antropocentrismo a un ecocentrismo. Para Jonas hace falta una nueva ética orientada al futuro y sus problemas bioéticos de Siqueira (2001) en su ensayo sobre el filósofo alemán haciendo un recuento propone que todas las éticas tradicionales obedecían a premisas que se interrelacionaban mutuamente y que eran las siguientes:

1) La condición humana, resultante de la naturaleza del hombre y de las cosas, permanecía fundamentalmente inmutable para siempre.

2) Con base en ese presupuesto, se podía determinar con claridad y sin dificultad el bien humano.

3) El alcance de la acción humana y de su consecuente responsabilidad estaba perfectamente delimitado.

Todo bien o mal que su capacidad inventiva pudiera proporcionar, se encontraba siempre dentro de los límites de la acción del ser humano, sin afectar la naturaleza de las cosas extrahumanas. Antes la naturaleza no era objeto de responsabilidad humana, pues cuidaba de sí misma. De hecho, pensábamos en una época que la siempre generosa y potente naturaleza podía cuidarse de sí misma y la reflexión ética se centraba en el hombre y las decisiones que influían en su propia vida. A cambio de los antiguos imperativos éticos, entre los cuales el imperativo kantiano constituye el parámetro ejemplar, recordemos el "Actúa de tal modo que el principio de tu acción se transforme en una ley universal", Jonas propone un nuevo imperativo: "Actúa de tal modo que los efectos de tu acción sean compatibles con la permanencia de una vida humana auténtica", o expresándolo de modo negativo: "No pongas en peligro la continuidad indefinida de la humanidad en la Tierra" (Sánchez Pascual, 1994; citado en el prólogo a la obra de Jonas, 1995). El filósofo Virilio afirmaba "hoy, por hoy, las nuevas tecnologías son portadoras de un cierto tipo de accidente, y un accidente que ya no es local o está puntualmente situado, como el naufragio del Titanic o el descarrilamiento de un tren, sino un accidente general, un accidente que afecta inmediatamente a la totalidad del mundo" (Virilio, 1997; citado por Onfray, 2005).

Jonas plantea una serie de interrogantes críticas. Con respecto a la prolongación de la vida humana se pregunta: ¿Hasta qué punto esto es deseable? Sobre el control de la conducta humana: ¿Debemos inducir sentimientos de felicidad o placer en la vida de las personas a través de estímulos químicos? En relación a la manipulación genética, donde el hombre toma en sus manos su propia evolución: ¿Estaremos capacitados para el papel de creadores? ¿Quiénes serán los escultores de la nueva imagen del hombre? ¿Según qué criterios y en base a qué modelos? ¿El hombre tendrá el derecho de cambiar el patrimonio genético del propio hombre?

Y nos advierte:

Ante un potencial casi escatológico de nuestra tecnología, la ignorancia sobre las últimas consecuencias será, por sí sola, razón suficiente para una moderación responsable (...) Hay otro aspecto digno de mencionarse, los no nacidos carecen de poder (...) ¿Qué fuerza debe representar el futuro en el presente?" (Jonas, 1995, citado por de Siquiera, 2009, p. 173). 
Para este autor estamos frente a un poder tan extraordinario de transformaciones y desprovistos de reglas que ordenen las acciones humanas. Ese enorme desajuste sólo podrá repararse, de acuerdo con Jonas, mediante la formulación de una nueva Ética. Pero para que haya responsabilidad, es preciso que exista un sujeto consciente (de Siqueira, 2001). Lo que ocurre es que el imperativo tecnológico basado en una racionalidad instrumental elimina la conciencia ética (y ecológica), elimina al sujeto, elimina la libertad en provecho de un determinismo y de un utilitarismo más que riesgoso, hasta necrófilo en el sentido de Erich Fromm: "La persona con orientación necrófila se siente atraída y fascinada por todo lo que no vive, por todo lo muerto" (Fromm, 2016, p. 42). Seguidamente dice: "La tendencia a conservar la vida y a luchar contra la muerte es la forma más elemental de la orientación biófila" (Fromm, 2016, p. 51). Son personas productivas, prefieren construir que conservar o destruir, "... quieren moldear e influir por el amor, por la razón, por su ejemplo, no por la fuerza" (Fromm, 2016, p. 53). En la misma línea el filósofo Onfray (2005) advierte "hoy en día, el mundo de la técnica se opone de tal manera al de la naturaleza que se puede temer que echemos a perder el orden natural. Los progresos, proponiéndose un mejor dominio de la naturaleza, llegan en ocasiones a maltratarla, desfigurarla, incluso destruirla" (p. 100). Por eso Jonas nos recuerda que alejar el peligro es una tarea permanente (Jonas, 1993 citado en Onfray, 2005).

En su análisis sobre Jonas, el ya mencionado profesor Gómez precisa:
Asistimos a un cambio de época, en la que la política se pone al servicio de la economía y en la que ésta se va a basar cada vez más en el consumo que en la producción. Los medios de comunicación (y las redes ahora) utilizan, cada vez más, una realidad virtualizada donde los acontecimientos son manipulados y seleccionados (los llamados fake news y la posverdad), publicitados o escondidos en función de los intereses del poder ideológico y financiero $(2015, \text { p. } 1)^{1}$.

Y continúa luego señalando que "la promesa del progreso tecnológico ha devenido en amenaza; sus consecuencias medioambientales han propiciado la aparición de la llamada conciencia ecológica, cuya concreción teórica conforma la ecoética" (Jonas, 1993 citado en Onfray, 2005, p.1). Se estima, por ejemplo, una pérdida de casi el $60 \%$ de los animales en los últimos cuarenta años ${ }^{2}$. Aunque la educación y la libertad de información han sido hasta ahora las vías para una creciente concientización, esto es algo que está siendo amortiguado -nos recuerda Gónzales- por el enorme peso de los grupos económico-financieros y sus lobbies, que tienen una gran influencia sobre buena parte de las instituciones científicas y comités nacionales e internacionales de control y evaluación de riesgos (Jonas, 1993, citado por Onfray, 2005. p. 4). Sumemos a eso el poder de los medios y de la publicidad y tendremos una razón más para temer en esta poca concientización.

Zygmunt Bauman, sociólogo y filósofo polaco de origen judío (quien acuñara

119 de las empresas multinacionales que agreden al ambiente y a los derechos humanos son socios o participantes en el Foro Económico Mundial: Carbon Majors, Chevron, Exxon, Mpnsanto, Nestlé, Glencore, VW, entre otras.

Fuente: https://www.nuevatribuna.es/articulo/sostenibilidad/20-casos-multinacionales-agreden-medioambiente-derechos-humanos/20180118183317147455.html 
el concepto de modernidad líquida para referirse a sociedades globales, capitalistas, hiper tecnológicas, y de muchos cambios sociales desde los años 60 aproximadamente) en su libro Vida de consumo propone que las personas nos hemos vuelto una masa de consumidores engañados, seducidos, arrastrados y manipulados todo el tiempo por la publicidad (Bauman, 2007). Inclusive nuestros vínculos están variando violentamente. Al respecto Bauman (2007) señala:

Los clientes habituales de las agencias de citas por internet, engolosinados por las prácticas del mercado, no se sienten nada cómodos en compañía de seres humanos de carne y hueso. El tipo de productos con los que fueron entrenados para socializar son para el tacto, pero no tienen manos para tocar (p. 31).

Jonas fue discípulo del famoso Martín Heidegger quien en su conferencia de 1953 titulada: "La cuestión concerniente a la tecnología", afirmaba que nuestra tecnología no era simplemente un conglomerado de dispositivos ingeniosos, sino que "revela algo fundamental sobre nuestra existencia" (Bakewell, 2015, p. 504). Por tanto, hay que pensar el tema de manera filosófica y no solamente técnica o económica. Y si bien la tecnología en la época de Heidegger involucraba apenas máquinas de escribir, proyectores de película, cámaras fotográficas y grandes coches, él mostraba ya entonces su preocupación por el tema, preocupación que -quizá- también heredó Jonas. "Investigarla con propiedad es llegar a cuestiones mucho más profundas sobre cómo trabajamos, cómo ocupamos la tierra y cómo "somos" en relación al Ser" (Bakewell, 2015, p. 504). ${ }^{2}$

Si bien la tecnología es necesaria e inevitable debido a la creatividad y curiosidad humana, debemos ser conscientes de sus alcances y de sus riesgos también. En este mundo cibernético y ya de robots de pronto las relaciones humanas cálidas están debilitándose, estando como estamos todo el día conectados a máquinas y aplicaciones, vamos perdiendo ese sabor humano que es parte importante del sentido de la vida (Arboccó de los Heros, 2019). Viktor Frankl, creador de la logoterapia o terapia a través del sentido, es claro al advertirnos: "Desde Auschwitz sabemos de lo que el hombre es capaz y desde Hiroshima, lo que está en juego" (Frankl, 1984 citado en García, 2006).

\section{TRABA J O D E AMPO (ENTREVISTAS)}

Entre los meses de mayo y junio del año 2020 se realizaron ocho entrevistas centrándonos en cuatro puntos a considerar sobre el tema (responsabilidad tecnológica). A continuación, presentamos, a manera de síntesis, las respuestas de los participantes a cuatro preguntas que consideramos principales: tecnológica? (conocimiento del tema)
a. ¿Qué es la responsabilidad
b. ¿Considera que se vivencia lo suficiente? y ¿por qué cree que pasa esto? (impacto e importancia del tema)
c. ¿Qué medidas o estrategias

2 Bakewell refiere que en 1954 (un año después de la conferencia de Heidegger) en el libro El existencialismo y los problemas modernos, el autor alemán Friedrich Heinemann, advertía de que la inminente "máquina de computar ultrarrápida" suscitaría una "cuestión realmente existencial", es decir, la de cómo podrían seguir siendo libres los humanos). Heinemann no podía haber tenido más razón, según Bakewell 
se podrían emplear para que este tema se vivencie con más sentido? (posibilidades)

d. ¿Qué idea de ser humano se promueve hoy? ¿Qué rol juegan los valores clásicos? (indagación antropológica y axiológica)

Las respuestas pasaron tanto por un análisis descriptivo como por un análisis crítico argumentativo.

\section{Respuestas encontradas y características de los entrevistados:}

\begin{tabular}{|c|c|c|c|c|}
\hline & $\begin{array}{l}\text { ENTREVISTADO } \\
\mathbf{1} \\
\text { (Hombre, } 39 \text { años, } \\
\text { antropólogo) }\end{array}$ & $\begin{array}{l}\text { ENTREVISTADO } \\
\mathbf{2} \\
\text { (Hombre, } 39 \text { años, } \\
\text { Gestor Empresarial) }\end{array}$ & $\begin{array}{l}\text { ENTREVISTADO } \\
\mathbf{3} \\
\text { (Hombre, } 32 \text { años, } \\
\text { comunicador) }\end{array}$ & $\begin{array}{l}\text { ENTREVISTADO } \\
\mathbf{4} \\
\text { (Hombre, } 40 \text { años, } \\
\text { psicólogo) }\end{array}$ \\
\hline $\begin{array}{l}\text { PGTA 1 } \\
\text { ¿Qué es? } \\
\text { (sentido) }\end{array}$ & $\begin{array}{l}\text { Está asociado al } \\
\text { uso sostenible y } \\
\text { amigable de la tec- } \\
\text { nología y sus re- } \\
\text { cursos tanto con } \\
\text { el medio ambiente } \\
\text { como con los de- } \\
\text { rechos culturales, } \\
\text { sociales y huma- } \\
\text { nos en general }\end{array}$ & $\begin{array}{l}\text { Políticas de creci- } \\
\text { miento tecnoló- } \\
\text { gico a favor de la } \\
\text { especie humana } \\
\text { porque aún hay } \\
\text { mucha gente que } \\
\text { padece hambre y } \\
\text { depreda el sistema } \\
\text { en que vivimos }\end{array}$ & $\begin{array}{l}\text { Es saber qué hacer } \\
\text { con nuestros des- } \\
\text { perdicios electró- } \\
\text { nicos y aparatos. }\end{array}$ & $\begin{array}{l}\text { Todos los avances } \\
\text { que nos permite la } \\
\text { ciencia y su parte } \\
\text { aplicativa, la tec- } \\
\text { nología, deben es- } \\
\text { tar comprometidas } \\
\text { con el crecimiento } \\
\text { y desarrollo de la } \\
\text { humanidad. Los } \\
\text { avances nos traen } \\
\text { progreso y nos ha- } \\
\text { cen la vida más } \\
\text { fácil y nos ayudan } \\
\text { a ser mejores per- } \\
\text { sonas, pero lo ne- } \\
\text { fasto es su utilidad } \\
\text { en la creación de } \\
\text { armas y virus. }\end{array}$ \\
\hline $\begin{array}{l}\text { PGTA } 2 \\
\text { ¿Por qué } \\
\text { no es } \\
\text { vivenciada } \\
\text { lo } \\
\text { suficiente? }\end{array}$ & $\begin{array}{l}\text { El concepto no } \\
\text { está comunicado } \\
\text { ni entendido por } \\
\text { mucha gente y, } \\
\text { por otro lado, los } \\
\text { términos relacio- } \\
\text { nados con respon- } \\
\text { sabilidad (empre- } \\
\text { sarial, ambiental, } \\
\text { social) se refieren } \\
\text { a lo mismo, por lo } \\
\text { que muchas veces } \\
\text { "nuevos" concep- } \\
\text { tos no hacen más } \\
\text { que distorsionar la } \\
\text { comprensión y el } \\
\text { interés del público } \\
\text { en general }\end{array}$ & $\begin{array}{l}\text { Se practica muy } \\
\text { poco en el mundo } \\
\text { porque la tecnolo- } \\
\text { gía está al servicio } \\
\text { del modelo capita- } \\
\text { lista que depreda } \\
\text { el ambiente. En el } \\
\text { Perú solo el } 2 \% \text { de } \\
\text { la energía que se } \\
\text { consume es na- } \\
\text { tural, el resto es } \\
\text { convencional. La } \\
\text { tecnología crece, } \\
\text { pero para que el } \\
\text { sistema empresa- } \\
\text { rial siga creciendo. }\end{array}$ & $\begin{array}{l}\text { Porque el Estado } \\
\text { no concientiza } \\
\text { para que las per- } \\
\text { sonas tengan claro } \\
\text { qué hacer con la } \\
\text { basura tecnoló- } \\
\text { gica. }\end{array}$ & $\begin{array}{l}\text { Creo que, si se } \\
\text { vive la responsabi- } \\
\text { lidad tecnológica, } \\
\text { aunque como sus } \\
\text { proyectos van no } \\
\text { siempre en la mis- } \\
\text { ma dirección del } \\
\text { hacer dinero. Y ya } \\
\text { sabemos que pasa } \\
\text { cuando buscamos } \\
\text { solo dinero y no } \\
\text { real progreso. }\end{array}$ \\
\hline
\end{tabular}




\begin{tabular}{|c|c|c|c|c|}
\hline $\begin{array}{l}\text { PGTA } 3 \\
\text { ¿Qué } \\
\text { estrategias } \\
\text { debemos } \\
\text { considerar } \\
\text { para viven- } \\
\text { ciarla? }\end{array}$ & $\begin{array}{l}\text { Creo que, en primer } \\
\text { lugar, es conocer y } \\
\text { hacer una distin- } \\
\text { ción del término } \\
\text { con otras responsa- } \\
\text { bilidades, posicionar } \\
\text { el concepto tam- } \\
\text { bién implicará dis- } \\
\text { cutirlo y difundirlo. } \\
\text { Esta tarea puede } \\
\text { realizarse tanto } \\
\text { desde los ámbitos } \\
\text { públicos, privados } \\
\text { como de la socie- } \\
\text { dad civil. }\end{array}$ & $\begin{array}{l}\text { El sistema económi- } \\
\text { co capitalista se ha } \\
\text { disparado y tendría } \\
\text { que haber políticas } \\
\text { de responsabilidad } \\
\text { tecnológica. Y si hay } \\
\text { no las conozco. Y } \\
\text { no se sienten. Es } \\
\text { como ir "contra la } \\
\text { corriente". El tema } \\
\text { ambiental involu- } \\
\text { cra trabajar con las } \\
\text { grandes corpora- } \\
\text { ciones y a muchas } \\
\text { de éstas no les con- } \\
\text { viene. Por eso hay } \\
\text { que comenzar en } \\
\text { casa, como sujetos } \\
\text { individuales hacer } \\
\text { nuestra pequeña } \\
\text { contribución. Pero } \\
\text { las políticas de RT } \\
\text { es casi imposible } \\
\text { que realmente se } \\
\text { den, todo es puro } \\
\text { maquillaje. }\end{array}$ & $\begin{array}{l}\text { Buscar mecanismos } \\
\text { de acumulación de } \\
\text { desperdicios tec- } \\
\text { nológicos de forma } \\
\text { personal, familiar o } \\
\text { a nivel social }\end{array}$ & $\begin{array}{l}\text { Hay dos grandes } \\
\text { propuestas: } \\
\text { a. La normatividad } \\
\text { del Estado para evi- } \\
\text { tar abuso de que la } \\
\text { tecnología haga lo } \\
\text { que quiera } \\
\text { b. Depende mucho } \\
\text { de lo que quiera } \\
\text { consumir la gente. Y } \\
\text { eso ya depende del } \\
\text { trabajo personal y } \\
\text { de los pequeños en } \\
\text { casa. Hay avances } \\
\text { tecnológicos que } \\
\text { no tienen nada de } \\
\text { útil y quizá la gente } \\
\text { no los requeriría si } \\
\text { a temprana edad } \\
\text { esas mismas per- } \\
\text { sonas aprendieran } \\
\text { que no tienen nada } \\
\text { de bueno. }\end{array}$ \\
\hline $\begin{array}{l}\text { PGTA 4 } \\
\text { ¿Qué idea } \\
\text { d e s e r } \\
\text { humano se } \\
\text { promueve } \\
\text { hoy? ¿Qué } \\
\text { rol juegan } \\
\text { los valores } \\
\text { clásicos? }\end{array}$ & $\begin{array}{l}\text { Un ideal de la } \\
\text { humanidad que } \\
\text { desde hace déca- } \\
\text { das viene siendo } \\
\text { construido, repro- } \\
\text { ducido y aceptado } \\
\text { en la cultura con- } \\
\text { temporánea es la } \\
\text { promovida por el } \\
\text { mercado la cual } \\
\text { se basa en la idea } \\
\text { del emprendimiento } \\
\text { como valor asocia- } \\
\text { do al éxito. La cul- } \\
\text { tura del capital y la } \\
\text { empresa definen al } \\
\text { emprendedor no solo } \\
\text { como un motor de } \\
\text { riqueza, sino como } \\
\text { una moralidad, una } \\
\text { necesidad de ser para } \\
\text { el bienestar de la } \\
\text { sociedad. }\end{array}$ & $\begin{array}{l}\text { Se promueve hoy } \\
\text { la imagen de un ser } \\
\text { consumista. Sin } \\
\text { consciencia de lo } \\
\text { que pasa en el mun- } \\
\text { do. No solo el mun- } \\
\text { do se está cayendo } \\
\text { a pedazos sino el } \\
\text { ser humano, y la } \\
\text { sociedad. Hay poca } \\
\text { consciencia porque } \\
\text { a las grandes corpo- } \\
\text { raciones no le inte- } \\
\text { resa que tampoco } \\
\text { lo sepamos. }\end{array}$ & $\begin{array}{l}\text { Se promueve la } \\
\text { imagen de ser hu- } \\
\text { mano que está } \\
\text { constantemente } \\
\text { aprendiendo, que } \\
\text { no ve las cosas ma- } \\
\text { las, que debe salir } \\
\text { adelante, que debe } \\
\text { esforzarse. Se pro- } \\
\text { mueve que "todo } \\
\text { lo podemos" y que } \\
\text { no hay que ver las } \\
\text { dificultades sino las } \\
\text { oportunidades. } \\
\text { Valores clásicos } \\
\text { como la caridad } \\
\text { o solidaridad, o e } \\
\text { compartir (donde } \\
\text { no hay ganancia) } \\
\text { se están perdiendo } \\
\text { porque estamos } \\
\text { constantemente } \\
\text { buscando oportuni- } \\
\text { dades y ganancias. } \\
\text { Por eso andamos } \\
\text { másindividualistas. }\end{array}$ & $\begin{array}{l}\text { Se mueve el rol de } \\
\text { hombre productivo, } \\
\text { el hombre utilitario. } \\
\text { Mientras más gene- } \\
\text { re, más produzca } \\
\text { es más valioso y si } \\
\text { encima eso lo puede } \\
\text { demostrar u ostentar } \\
\text { Mejor aún. El que no } \\
\text { produce es conside- } \\
\text { rado inservible y es } \\
\text { recluido. } \\
\text { Por eso los niños } \\
\text { y los ancianos son } \\
\text { recluidos porque no } \\
\text { producen. } \\
\text { Los valores clási- } \\
\text { cos son como los } \\
\text { libros clásicos, no } \\
\text { pasan de moda por- } \\
\text { que tienen secre- } \\
\text { tos esenciales de } \\
\text { la vida. Lo que más } \\
\text { puede ayudar a una } \\
\text { persona a sentirse } \\
\text { fuerte. Sólida esta- } \\
\text { ble, enraizada con } \\
\text { su existencia, son los } \\
\text { valores, que te dan } \\
\text { en casa. Buenas raí- } \\
\text { ces cualquier viento } \\
\text { no te lleva. }\end{array}$ \\
\hline
\end{tabular}




\begin{tabular}{|c|c|c|c|c|}
\hline & $\begin{array}{l}\text { ENTREVISTADO } \\
\mathbf{5} \\
\text { (Hombre, } 60 \text { años, } \\
\text { Psicólogo) }\end{array}$ & $\begin{array}{l}\text { ENTREVISTADO } \\
\mathbf{6} \\
\text { (Mujer, } 56 \text { años, Psi- } \\
\text { cóloga) }\end{array}$ & $\begin{array}{l}\text { ENTREVISTADO } \\
\mathbf{7} \\
\text { (Hombre, } 55 \text { años, } \\
\text { Psicólogo) }\end{array}$ & $\begin{array}{l}\text { ENTREVISTADO } \\
\mathbf{8} \\
\text { (Mujer, } 27 \text { años, Di- } \\
\text { señadora Gráfica) }\end{array}$ \\
\hline $\begin{array}{l}\text { PGTA 1 } \\
\text { ¿Qué es? } \\
\text { (sentido) }\end{array}$ & $\begin{array}{l}\text { Está en relación a } \\
\text { la responsabilidad } \\
\text { social que todo ser } \\
\text { humano necesita } \\
\text { desarrollar como } \\
\text { competencia de } \\
\text { inteligencia emo- } \\
\text { cional. } \\
\text { Hoy la tecnología } \\
\text { tiene un valor signi- } \\
\text { ficativo y el sentido } \\
\text { tecnológico hace } \\
\text { posible que el ser } \\
\text { humano se rein- } \\
\text { vente. }\end{array}$ & $\begin{array}{l}\text { Ahora que la tecno- } \\
\text { logía es una herra- } \\
\text { mienta importante } \\
\text { he indispensable } \\
\text { tenemos que ser } \\
\text { cautos para así } \\
\text { poder servirnos de } \\
\text { esta y apoyarnos } \\
\text { y ayudarnos y no } \\
\text { convertirnos en } \\
\text { dependiente de la } \\
\text { tecnología. }\end{array}$ & $\begin{array}{l}\text { El desarrollo tec- } \\
\text { nológico es muy } \\
\text { bueno el problema } \\
\text { es que avanza mu- } \\
\text { cho más rápido en } \\
\text { relación a las nece- } \\
\text { sidades que tienen } \\
\text { que cubrirse para } \\
\text { responder a esa } \\
\text { tecnología. Parte de } \\
\text { los problemas es la } \\
\text { demanda de tecno- } \\
\text { logía hace a las per- } \\
\text { sonas vulnerables } \\
\text { por no contar con } \\
\text { las herramientas de } \\
\text { vanguardia; esto se } \\
\text { siente más en la } \\
\text { población adulta, } \\
\text { adulta mayor o per- } \\
\text { sonas con alguna } \\
\text { discapacidad que } \\
\text { no está prepara- } \\
\text { da para este reto. } \\
\text { Está hecha para } \\
\text { todas las personas, } \\
\text { pero no siempre } \\
\text { se cumple con ese } \\
\text { requisito. El otro } \\
\text { problema es que } \\
\text { nuestra sociedad } \\
\text { no siempre tiene } \\
\text { las posibilidades de } \\
\text { entrenarse, somos } \\
\text { una sociedad con } \\
\text { muchas limitan- } \\
\text { tes. Es importante, } \\
\text { pero va más rápido } \\
\text { a las necesidades } \\
\text { de las personas y } \\
\text { las capacidades } \\
\text { para implementar } \\
\text { las habilidades para } \\
\text { responder a la tec- } \\
\text { nología. } \\
\text { La responsabilidad } \\
\text { tiene que ver con } \\
\text { el impacto social, } \\
\text { psicológico en las } \\
\text { personas. }\end{array}$ & $\begin{array}{l}\text { Significa ser pru- } \\
\text { dente con lo que } \\
\text { comparte y se lee. } \\
\text { Respetar lo que las } \\
\text { demás personas } \\
\text { comparten en sus } \\
\text { redes sociales. } \\
\text { Es una gran fuente } \\
\text { de investigación y } \\
\text { se puede aprender } \\
\text { muchas cosas, se } \\
\text { usa para cosas que } \\
\text { favorezcan la vida } \\
\text { de las personas. }\end{array}$ \\
\hline
\end{tabular}




\begin{tabular}{|c|c|c|c|c|}
\hline $\begin{array}{l}\text { PGTA } 2 \\
\text { ¿Por qué } \\
\text { n o e s } \\
\text { vivenciada } \\
\text { l } \\
\text { suficiente? }\end{array}$ & $\begin{array}{l}\text { Hoy es la vivencia } \\
\text { de la sociedad de } \\
\text { manera tecnoló- } \\
\text { gica, se necesita } \\
\text { asumir con respon- } \\
\text { sabilidad la socie- } \\
\text { dad de tal manera } \\
\text { que se participe de } \\
\text { manera positiva, el } \\
\text { mal uso de ésta de- } \\
\text { sarrolla conductas } \\
\text { adictivas en niños } \\
\text { adolescentes he } \\
\text { incluso en adultos. }\end{array}$ & $\begin{array}{l}\text { La responsabilidad } \\
\text { tecnológica tendría } \\
\text { que ir unido a la } \\
\text { ética para lo cual } \\
\text { tendríamos que } \\
\text { promover compor- } \\
\text { tamientos morales. }\end{array}$ & $\begin{array}{l}\text { Somos una socie- } \\
\text { dad que vive muy } \\
\text { rápido, primero es } \\
\text { la parte del conoci- } \\
\text { miento y la segunda } \\
\text { es que no tenemos } \\
\text { la capacidad de es- } \\
\text { tar a la altura del } \\
\text { desarrollo tecnoló- } \\
\text { gico, no hay tiempo } \\
\text { para adaptarse a la } \\
\text { primera tecnología } \\
\text { y ya estamos pa- } \\
\text { sando a la segunda. } \\
\text { La tecnología avan- } \\
\text { za tan rápido que } \\
\text { las empresas no se } \\
\text { comprometen a es- } \\
\text { tabilizar los produc- } \\
\text { tos tecnológicos } \\
\text { con ciertas carac- } \\
\text { terísticas. No hay } \\
\text { un trabajo para dar } \\
\text { los parámetros de } \\
\text { la responsabilidad } \\
\text { tecnológica. }\end{array}$ & $\begin{array}{l}\text { Cada uno tiene su } \\
\text { propia forma de } \\
\text { entender las co- } \\
\text { sas tecnológicas, } \\
\text { depende de uno el } \\
\text { uso. } \\
\text { Debe ser usada } \\
\text { para el bien común } \\
\text { y para cosas positi- } \\
\text { vas que aporten a } \\
\text { los demás. }\end{array}$ \\
\hline $\begin{array}{l}\text { PGTA } 3 \\
\text { ¿ a u é } \\
\text { estrategias } \\
\text { debemos } \\
\text { considerar } \\
\text { p a r a } \\
\text { vivenciarla? }\end{array}$ & $\begin{array}{l}\text { Las estrategias } \\
\text { cognitivas están } \\
\text { ligadas a como se } \\
\text { piensa frente a la } \\
\text { tecnología y cómo } \\
\text { afronta con res- } \\
\text { ponsabilidad ese } \\
\text { reto tecnológico, } \\
\text { el pensamiento } \\
\text { positivo brinda } \\
\text { respuestas emo- } \\
\text { cionales positivas } \\
\text { frente a esa viven- } \\
\text { cia. Existen pensa- } \\
\text { mientos distorsio- } \\
\text { nados frente a la } \\
\text { tecnología y frente } \\
\text { a la responsabili- } \\
\text { dad, puede llevar a } \\
\text { emociones negati- } \\
\text { vas como ansiedad } \\
\text { o depresión. }\end{array}$ & $\begin{array}{l}\text { La responsabilidad } \\
\text { tecnológica tendría } \\
\text { que ir unido a la éti- } \\
\text { ca lo cual nos per- } \\
\text { mite unir y tendría- } \\
\text { mos que promover } \\
\text { comportamientos } \\
\text { morales. Entre las } \\
\text { estrategias se pue- } \\
\text { de incluir un plan } \\
\text { de sensibilización, } \\
\text { capacitación para } \\
\text { que se dosifique el } \\
\text { uso de la tecnología } \\
\text { en especial en la } \\
\text { población joven. }\end{array}$ & $\begin{array}{l}\text { La educación la } \\
\text { sensibilización, el } \\
\text { ser humano se es- } \\
\text { fuerza muy poco } \\
\text { en adaptarse, la } \\
\text { sociedad avanza } \\
\text { tan rápido no tie- } \\
\text { ne la oportunidad } \\
\text { de pensarlos. Este } \\
\text { avance tan rápido } \\
\text { genera personali- } \\
\text { dades hiperestimu- } \\
\text { ladas, fenómenos } \\
\text { que afectan cogni- } \\
\text { tivamente. } \\
\text { Cada vez nos volve- } \\
\text { mos más individua- } \\
\text { lizados nos cierra } \\
\text { más la posibilidad } \\
\text { de sociabilizar, fan- } \\
\text { taseando sobre rea- } \\
\text { lidades virtuales que } \\
\text { tienen que ver con la } \\
\text { despersonalización } \\
\text { en algunos casos. } \\
\text { Las estrategias } \\
\text { cognitivas serian } \\
\text { regresar a los orí- } \\
\text { genes, regresar a } \\
\text { la pausa, a la co- } \\
\text { municación en el } \\
\text { hogar, regresar. }\end{array}$ & $\begin{array}{l}\text { Respetarse entre sí } \\
\text { y mejorar cada día } \\
\text { aprendiendo de los } \\
\text { demás, si hablamos } \\
\text { de redes sociales, } \\
\text { si hablamos de ar- } \\
\text { tefactos como por } \\
\text { ejemplo un reloj o } \\
\text { aplicativos revisar } \\
\text { cada quien los re- } \\
\text { sultados y avanzar } \\
\text { positivamente. }\end{array}$ \\
\hline
\end{tabular}




\begin{tabular}{|c|c|c|c|c|}
\hline & & & $\begin{array}{l}\text { a buscar tranqui- } \\
\text { lidad paz, alejarse } \\
\text { de la ciudad, regu- } \\
\text { lación del estado de } \\
\text { ansiedad, control } \\
\text { de los impulsos. } \\
\text { Tema de educación } \\
\text { y motivar a las per- } \\
\text { sonas a través de } \\
\text { una buena forma- } \\
\text { ción del ciudadano, } \\
\text { y a que haga em- } \\
\text { pleo como gestión } \\
\text { de la educación } \\
\text { individual, como } \\
\text { hacen en otros } \\
\text { países el uso del } \\
\text { concepto de inte- } \\
\text { ligencia emocional, } \\
\text { regulación de los } \\
\text { estados emociona- } \\
\text { les, entrenamiento } \\
\text { asertivo. }\end{array}$ & \\
\hline $\begin{array}{l}\text { PGTA } 4 \\
\text { ¿Qué idea } \\
\text { d e s e r } \\
\text { humano se } \\
\text { promueve } \\
\text { hoy? ¿Qué } \\
\text { rol juegan } \\
\text { los valores } \\
\text { clásicos? }\end{array}$ & $\begin{array}{l}\text { Cambio significati- } \\
\text { vo de la sociedad, la } \\
\text { idea de ser humano } \\
\text { hoy es estar ligado } \\
\text { a la tecnología y } \\
\text { ciencia. Al manejo } \\
\text { de instrumentos in- } \\
\text { formáticos permite } \\
\text { desarrollar habili- } \\
\text { dades, capacidades } \\
\text { y competencias. } \\
\text { Hoy en día el ser } \\
\text { humano está liga- } \\
\text { do a la tecnología } \\
\text { y es una realidad } \\
\text { por lo tanto ne- } \\
\text { cesitamos orientar } \\
\text { o reorientar a los } \\
\text { niños y adolescen- } \\
\text { tes en ese aspecto } \\
\text { para que ese valor } \\
\text { importante de res- } \\
\text { ponsabilidad social } \\
\text { se genere en ellos y } \\
\text { haga que aprendan } \\
\text { a manejar la infor- } \\
\text { mática o mecanis- } \\
\text { mos tecnológicos } \\
\text { de manera positiva, } \\
\text { técnicas de modifi- } \\
\text { cación adecuados } \\
\text { en la conducta a } \\
\text { fin de prevenir que } \\
\text { existan conductas } \\
\text { adictivas hacia los }\end{array}$ & $\begin{array}{l}\text { En medida que la } \\
\text { ciencia y la tecno- } \\
\text { logía aumentan nos } \\
\text { incluimos en una } \\
\text { sociedad de cono- } \\
\text { cimiento es decir } \\
\text { nos incorporamos } \\
\text { a un proceso de } \\
\text { producción y a un } \\
\text { desarrollo social. } \\
\text { Replantearnos si } \\
\text { nos está ayudan- } \\
\text { do a ser mejores, } \\
\text { la tecnología está } \\
\text { ahí para que noso- } \\
\text { tros hagamos uso } \\
\text { de esta, pero con } \\
\text { conciencia, ética y } \\
\text { responsabilidad y } \\
\text { todo depende de } \\
\text { nuestra formación } \\
\text { de valores. }\end{array}$ & $\begin{array}{l}\text { Una sociedad enfo- } \\
\text { cada en la inmedia- } \\
\text { tez, en el presente, } \\
\text { no hay futuro, no } \\
\text { planificamos a fu- } \\
\text { turo. } \\
\text { Nuestro país no } \\
\text { se caracteriza por } \\
\text { planificar sino por } \\
\text { vivir el presente. } \\
\text { No desarrollamos } \\
\text { talentos no desa- } \\
\text { rrollamos creativi- } \\
\text { dad, no nosotros } \\
\text { desarrollamos tec- } \\
\text { nología. } \\
\text { El ser humano de } \\
\text { ahora es muy me- } \\
\text { diático, muy aliena- } \\
\text { do, la globalización } \\
\text { en su máxima ex- } \\
\text { presión hace un ser } \\
\text { humano distante. } \\
\text { El ser humano de } \\
\text { hoy está más pre- } \\
\text { ocupado en ser } \\
\text { agentes técnicos } \\
\text { que aportar cono- } \\
\text { cimientos, revolver } \\
\text { problemas signifi- } \\
\text { cativos para el de- } \\
\text { sarrollo de nuestra } \\
\text { cultura y nuestra } \\
\text { sociedad. } \\
\text { La tecnología no }\end{array}$ & $\begin{array}{l}\text { Una persona que } \\
\text { siempre está bien } \\
\text { sin problemas, se } \\
\text { muestra siempre } \\
\text { feliz. } \\
\text { En estos tiempos } \\
\text { por la coyuntura, } \\
\text { la imagen en la } \\
\text { sociedad joven se } \\
\text { ha vuelto más real } \\
\text { mostrando que no } \\
\text { todos los días son } \\
\text { fáciles, y eso no está } \\
\text { mal }\end{array}$ \\
\hline
\end{tabular}




\begin{tabular}{|l|l|l|l|}
\hline $\begin{array}{l}\text { adictivas hacia los } \\
\text { medios informá- } \\
\text { ticos como todo } \\
\text { acto lúdico. } \\
\text { Es lo que se nece- } \\
\text { sita para promover } \\
\text { los valores clásicos } \\
\text { se apliquen junto } \\
\text { con la ética y la mo- } \\
\text { ral que son los que } \\
\text { van a fundamentar } \\
\text { la conducta y el } \\
\text { comportamiento } \\
\text { en los seres hu- } \\
\text { manos frente a la } \\
\text { tecnología y refor- } \\
\text { zando la responsa- } \\
\text { bilidad social frente } \\
\text { a la tecnología. }\end{array}$ & $\begin{array}{c}\text { es } \\
\text { ventaja, sino que } \\
\text { no estamos pre- } \\
\text { parados para asu- } \\
\text { mir con buenos } \\
\text { recursos afectivos } \\
\text { y emocionales en } \\
\text { esta sociedad que } \\
\text { avanza tan rápido. }\end{array}$ \\
\end{tabular}

3. ANÁlisis PSICO-SOCIOAXIOLÓGICO DE LAS RESPUESTAS

\section{P R I M ERA C UES T IÓ N : ¿QUÉ ENTIENDE USTED POR RESPONSABILIDAD TECNOLÓGICA?}

\section{a. Análisis Descriptivo}

En la primera pregunta, ¿qué es para usted la responsabilidad tecnológica? Las respuestas giran en torno al empleo de artefactos, aparatos y recursos que, si bien son útiles, tienen su lado negativo al producir muchos desperdicios, además de estar involucrados en la creación de armas e inclusive de virus (a propósito de la pandemia por Covid-19 que estamos viviendo) así como con la prudencia y el cuidado en el manejo de la información que se comparte en las llamadas redes sociales virtuales. Se señala un cierto desfase con algunos grupos humanos para quien la tecnología no llega o llega a duras penas (pobres, ancianos).

\section{b. Análisis Crítico argumentativo}

En la primera consulta realizada, la mayoría no tiene muy en claro el alcance exacto del concepto de responsabilidad tecnológica y por ende, solo se intuye su valor, más no se precisa. La mayoría lo relaciona al aporte que la tecnología tiene en las vidas de las personas y si bien hay una preocupación de que los avances y utilidades no lleguen a todos por igual (por ejemplo ancianos, discapacitados, pobres) o a la cantidad de desperdicios que producimos al ser la tecnología algo rápidamente intercambiable y desechable, son pocos los que señalan la responsabilidad que tenemos con el costo de la fabricación de esa tecnología como con su empleo y sus fines, y el impacto que tiene todo esto en el ambiente, al ser la tecnología, algo que tiende a contaminar mucho el ambiente y tener una caducidad cada vez más corta (obsolescencia programada). Las respuestas tienen en cuenta el concepto de tecnología más que el de responsabilidad.

\section{SEGUNDA CUESTIÓN: ¿POR QUÉ NO ES VIVENCIADA LO SUFICIENTE?}

\section{a. Análisis descriptivo}

En la segunda pregunta ¿̇por qué no es vivenciado lo suficiente? Nos señalan que hay varias razones, para unos los términos 
relacionados con responsabilidad (sea empresarial, ambiental, social) se refieren a lo mismo, otros señalan que sí se practica pero poco, porque la tecnología está al servicio del modelo capitalista y éste no tiene reparos en depredar el ambiente al buscar producir dinero como fin primordial. Alguno de los entrevistados refiere, y con razón, que una característica que tiene la tecnología es que avanza muy rápido y eso no siempre da tiempo para conocer y manejar correctamente la misma. Así mismo, menciona, porque el Estado no realiza un buen trabajo de concientización para que las personas tengan claro qué hacer con la basura tecnológica.

\section{b. Análisis crítico argumentativo}

Las respuestas brindadas muestran, como muchas veces vemos, que se responsabiliza al Estado y sus instituciones al no publicitar convenientemente este concepto y lo que conlleva y esto, en parte, porque no conviene a los intereses lucrativos de un modelo que prioriza la producción, la venta y el consumo de lo tecnológico. Nos hubiera gustado escuchar también sobre la propia responsabilidad, la individual y familiar, en temas axiológicos y éticos como el mencionado. La responsabilidad en el manejo de los recursos naturales y en el efecto colateral del empleo de ciertas tecnologías, si bien tiene una dimensión macro en las grandes corporaciones y políticas públicas y privadas también es propio de todos los individuos de colectivo humano. Como señaló uno de los entrevistados, la gente debe percatarse que hay "inventos" y productos que mucho de bueno, no tienen.

La tremenda vulnerabilidad de la naturaleza sometida a la intervención tecnológica del hombre muestra una situación inusitada, pues nada menos que toda la biósfera del planeta está expuesta a posibles alteraciones, lo cual hace imprescindible considerar que no sólo debe anhelarse el bien común, sino también el de toda la naturaleza más allá de la humana, es decir lo animal y lo vegetal (de Siqueira, 2001).

\section{TERCERA CUESTIÓN: ¿QUÉ ESTRATEGIAS DEBEMOS CONSIDERAR ENTONCES PARA VIVENCIARLA?}

\section{a. Análisis descriptivo}

Las respuestas que encontramos a esta tercera pregunta señalan que para posicionar el concepto habría que discutirlo y difundirlo desde los ámbitos tanto públicos como privados como de la sociedad civil. Tendría que haber políticas directas de responsabilidad tecnológica y que se sientan, aunque, considerar que es difícil porque esto involucra "ir contra la corriente". El tema ambiental, se menciona, por último, involucra trabajar con las grandes corporaciones y a muchas de éstas no les conviene, para sobre llevar eso hay que comenzar en casa, como sujetos individuales y así hacer nuestra pequeña contribución, aunque debe existir la normatividad del Estado para evitar el empleo indiscriminado y peligroso de la tecnología

Se señala que para poder vivienciarla adecuadamente depende mucho de lo que quiera consumir la gente, es decir de sus hábitos. Y eso ya depende del trabajo personal y sobre todo de los pequeños en casa. Un entrevistado recalca que hay avances tecnológicos que no tienen nada de útil y quizá la gente no los requeriría si a temprana edad esas mismas personas aprendieran que no tienen nada de bueno. Hay quienes sugieren la capacitación para que se dosifique el uso de la tecnología 
en especial en la población joven, así como pensamientos distorsionados frente a la tecnología y sus usos. Educar en lo emocional y en una convivencia que no dependa tanto de ella.

\section{b. Análisis crítico argumentativo}

Los entrevistados coinciden en que la práctica de valores como la responsabilidad tecnológica y el cuidado del ecosistema llegan a chocar con los valores del mercado y eso limita mayores esfuerzos por cuidar a nivel macro el ambiente. Me explico, si bien hay campañas llamadas "verdes" y se ve bien "la cultura del reciclaje" y del cuidado del ambiente, a nivel empresarial es sabido de fenómenos como el deterioro de la capa de ozono, la extinción de especies desde hace décadas (una pérdida de casi el 60\% de los animales en los últimos 40 años según cifras oficiales), el daño en los polos, la ruina de algunos yacimientos mineros, la contaminación de lagos y océanos, la polución ambiental y el cambio visible en montañas y nevados. Y esto porque los grandes empresarios y políticos continúan despreciando el discurso ambiental, considerarlo exagerado e inexacto y viendo la posibilidad de seguir extrayendo todo lo posible de la naturaleza comprometiendo, no solo a los lugareños de las zonas depredadas, sino a la naturaleza misma.

Pensamos que, dentro de las estrategias para promover esta nueva ética, como dice Hans Jonas, de la responsabilidad tecnológica bien haríamos en ser conscientes de esta obsolescencia de las cosas que hemos conversado durante este curso. Se calcula que esto de volver obsoletos los objetos que se manufacturan y venden, viene desde la década de los veinte del siglo pasado
(Arboccó de los Heros, 2017). iUn siglo bajo este régimen de consumo!

Ahora, ¿cuáles son las implicancias de todo esto? Pues el negocio no se detiene y tenemos a las personas comprando y comprando todo el tiempo productos cuya vida útil puede llegar a ser de algunos meses (como el caso de prendas de vestir o de artefactos del tipo "usar - tirar" o sea desechables) o de pocos años. Sin embargo, esto acarrea -si bien un buen negocio- una acumulación de basura pues muchos de estos productos no son reciclables. Nunca antes como en el siglo XX, el ser humano ha producido y acumulado tanta basura, qué duda cabe, cuyo impacto al ambiente es perjudicial cuando no nefasto. Daño que es muy probable esté detrás de muchos fenómenos climáticos que vemos viendo desde hace algunos años.

La ciencia crea nuevos modelos tecnológicos y la técnica crea nuevas líneas de objetivos científicos. Las cuestiones éticas se colocan hoy en el plano de las investigaciones llamadas básicas, pues el proyecto de saber lleva inevitablemente al hacer y al poder. En un contexto contemporáneo la pregunta kantiana "¿Qué puedo hacer?" debe contener otra: ¿Qué puedo hacer y qué puedo fabricar? (de Siqueira, 2001).

Ante eso tenemos que trabajar la parte afectiva tanto como la cognitiva del ser humano, y desde pequeños, por ejemplo, sensibilización frente a la tecnología, enseñarles a los jóvenes a razonar, analizar, que se hagan más responsables de sus acciones y de lo que consumen, enseñarles a respetar el espacio que compartimos, así como a los demás y recordar que la tecnología está al servicio de la mejora de la calidad de vida, nunca para acortarla, dañarla o destruirla. 


\section{CUARTA CUESTIÓN: ¿QUÉ IDEA DE SER HUMANO SE PROMUEVE HOY? ¿QUÉ ROL JUEGAN LOS VALORES CLÁSICOS?}

\section{a. Análisis descriptivo}

Los entrevistados señalan que un ideal de la humanidad que desde hace décadas viene siendo construido, reproducido y aceptado en la cultura contemporánea es la promovida por el mercado la cual se basa en la idea del emprendimiento como valor asociado al éxito. La cultura del capital y la empresa definen al emprendedor no solo como un motor de riqueza, sino como una moralidad, una necesidad de ser para el bienestar de la sociedad. Se promueve hoy la imagen de un ser consumista y sin consciencia de lo que pasa en el mundo. No solo el mundo se está cayendo a pedazos, nos refieren, sino el ser humano, y la sociedad en su conjunto. Hay poca consciencia porque a las grandes corporaciones no le interesa que tampoco lo sepamos. También nos responden los más jóvenes que se promueve la imagen de ser humano que está constantemente aprendiendo, que no ve las cosas malas, que debe salir adelante, que debe esforzarse para conseguir lo que quiere. Se promueve que "todo lo podemos" y que no hay que ver las dificultades sino las oportunidades. Nos mencionan que los valores clásicos como la caridad o solidaridad, o el compartir (donde no hay ganancia) se están perdiendo porque estamos constantemente buscando oportunidades y ganancias. Por eso andamos más individualistas. Se mueve el rol de hombre productivo, el hombre utilitario. Mientras más genere, más produzca es más valioso y si encima eso lo puede demostrar u ostentar mejor aún. El que no produce es considerado inservible y es recluido.
Sin embargo, los valores clásicos son como los libros clásicos, no pasan de moda porque tienen secretos esenciales de la vida. Lo que más puede ayudar a una persona a sentirse fuerte, sólida estable, enraizada con su existencia, son los valores, que te dan en casa, esas son las buenas raíces.

\section{b. Análisis crítico argumentativo}

En la cuarta y última pregunta, vemos que hay coincidencia en los entrevistados de cuarenta años a más sobre el modelo humano que en estas últimas décadas (época llamada de la posmodernidad) se ofrece. El hombre emprendedor, hedonista, que todo lo puede, que consume y que produce. Este es el modelo de "hombre exitoso". Algo alienado también, cortoplacista y apurado.

Nos gustó aquel comentario dado por un antropólogo que señaló lúcidamente que "la cultura del capital y la empresa definen al emprendedor no solo como un motor de riqueza, sino como una moralidad, una necesidad de ser para el bienestar de la sociedad". Hay pues una nueva lectura antropológica en la posmodernidad.

Hans Jonas señala que no solo se trata de la supervivencia física del hombre sino de la integridad de su esencia. No solo el ambiente está en peligro sino el hombre mismo y su identidad, tengamos presente que ya se habla de lo transhumano. El trashumanismo es un movimiento cultural internacional que tiene como objetivo transformar la condición humana mediante el desarrollo y la fabricación de tecnologías disponibles que mejoren las capacidades humanas, en lo físico y en lo psicológico. De hecho, las noticias internacionales nos informan que, en laboratorios de alta gama, ya se 
ha manipulado genéticamente a conejos, por poner un ejemplo, logrando que duerman y coman menos que el promedio o que cuyas crías sean más grandes y más fuertes. ¿Quién puede negar que esto sería el sueño de alguna mente deseosa de una población así a escala mundial? O peor aún ¿de soldados mejores equipados? También nos preguntamos, ¿en qué momento ese transhumano dejará ya de ser lo que conocíamos como una persona para ser otra especie nueva y distinta? ¿tendrán en cuenta la ética aquellos que manipulan la vida humana y animal? Recordemos que la propia evolución está en juego, así como su propio destino. Por eso disciplinas como la bioética, la tecnoética y la llamada ecoética son urgentes y deben estar presentes en las carpetas docentes para ser discutidas con las nuevas generaciones que serán los próximos ingenieros, genetistas, empresarios, políticos, comerciantes o biólogos.

El hombre de hoy está lleno de cables, audífonos, equipos celulares (a veces más de un equipo), lap top, tablets, cargadores, enchufes y toda una parafernalia que lo convierte en un ser lleno de prótesis tecnológicas. Nunca antes -pues no existía tanta tecnología al alcance claro- el ser humano ha estado lleno de tantas cosas que no siempre lo "conectan" con los demás y con la vida. A veces, hasta lo sacan de la realidad y lo transportan a mundos irreales de imágenes programadas como aquel juego virtual de los pokemones que debían ser atrapados en cualquier lugar. Pues, los "capturadores" se convirtieron en presas, muchos por la compulsiva caza, caían en piletas, huecos, zanjas, se estrellaban con postes o se tropezaban por las escaleras, en un mundo que nos acerca cada vez más al de las series de zombis (Arboccó de los Heros, 2016).
Sumado a esto, y para complicar más las cosas, disciplinas como el marketing y ahora el neuromarketing se cuelgan al empleo de los descubrimientos con propósitos de consumo masivo. En resumidas cuentas, este neuromarketing se puede definir como la aplicación de algunos hallazgos en las neurociencias al mundo de la mercadotécnica. Se presta atención a aspectos psicológicos como la percepción, la memoria, la atención y las emociones para incidir luego en la capacidad de decisión del consumidor. Demás está decir que los estudios son muy creativos e interesantes; se presentan estímulos diversos y se analizan las respuestas de las personas, se miden las reacciones psicofisiológicas y cerebrales y se llega a conclusiones sobre lo que atrae, agrada y motiva a un potencial cliente. Algunos ejemplos de esto a continuación: vas a un supermercado y te encontrarás con los productos de primera necesidad al fondo, así tendrás que recorrer pasillos llenos de "ofertas" antes de encontrar aquello para lo que fuiste. Colores llamativos y grandes cifras con precios sin redondear ("a sólo 99.90 en vez de colocar a sólo 100 soles) esto es porque 100 es un número de tres cifras mientras que 99 solo tiene dos y nos da la ilusión de ser un precio menor. La mayoría de las compras son emocionales más que racionales y apelan a necesidades básicas, cuasi infantiles., y eso lo saben los publicistas alertados. Si no hubiera "música ambiental" y mucho aromatizador es probable que el tiempo que pasáramos en las tiendas fuera más corto, pero es que el ambiente es tan grato que dan ganas de quedarse, además están las anfitrionas que nos dan a degustar algunos productos y nos hablan de las bondades de ciertos champús. La posición de los productos también ha sido estudiada, generalmente al alcance de tus ojos los productos que más se quieren vender (o son más 
caros) y abajito o muy arriba los demás. Uno suele mirar primero lo que está a la altura de la propia mirada. Y a la hora de hacer la cola para pagar encontraremos las golosinas, revistas, cigarrillos y otras chucherías que probablemente cojamos ya que la espera desespera, además suelen tener precios muy bajos. Como diría el Chapulín Colorado, "todo está fríamente calculado".

Lo que buscamos es reflexionar sobre la dimensión moral de todo esto. ¿Es correcto, conociendo cómo funciona el cerebro, manipular a las personas para que compren determinados productos? Porque detrás de esto está el buscar que las personas consuman ciertas cosas, ciertas marcas. ¿Es éticamente válido? ¿es el mejor empleo que se le puede dar a los hallazgos neurocientíficos? La ciencia no nos dirá nunca si algo es bueno o malo pues la ciencia básicamente describe y explica, pero es la actitud filosófica, y en particular, la orientación ética la que nos invita a reflexionar qué hacemos con aquella información alcanzada. Por eso Jonas dice que estos tiempos requieren de una nueva ética. Una ética que contemple el alcance de lo que la ciencia y la tecnología permiten hacer.

Nos parece que esta sociedad, manejada por un utilitarismo reduccionista y un "empresarialismo" salvaje, desvirtúan lo que de bueno tienen los descubrimientos en el campo de las neurociencias. Consciente o inconscientemente las grandes marcas están logrando conducir como borregos a millones de personas para que adquieran muchas cosas que posiblemente no necesitan, pero al conocer cómo funcionan ciertos mecanismos de la psique humana como la atención y las emociones, inciden en la ahora manipulada consciencia de las personas.
Un psicólogo entrevistado para este trabajo recalcó en la primacía de los valores clásicos que, si bien no siempre se promueven por las características de los sistemas económicos y políticos ya mencionados, son siempre vigentes, no caducan, y sientan las bases de unas buenas raíces, cuya siembra está en la casa. La familia, está clarísimo, ocupa un lugar central en el desarrollo de los hijos. Familias bien constituidas y educadas en valores morales e intelectuales suelen favorecer mejores resultados, pero también está claro que muchas familias son bastante disfuncionales lo que repercute negativamente en el aparato cognoscitivo, afectivo y axiológico de sus hijos. Además, estamos convencidos que el nivel educativo de los padres y la familia y el desarrollo moral suelen influir muy positivamente en la actitud y la valoración del niño y de la niña hacia el prójimo, la sociedad y la naturaleza en su conjunto. Así, por ejemplo, se ha encontrado que en el nivel de educación primaria, independientemente de la condición económica de la familia del niño, el nivel educativo de los padres se asocia de manera significativa con su rendimiento escolar (Beltrán y Seinfeld, 2012). Y lo axiológico también es algo actitudinal y producto del aprendizaje y precisamos además que cuando hablamos de educación no solo nos referimos al nivel de conocimientos que le vayan a brindar al pequeño. Cuando hablamos de educación hablamos desde una mirada holística: educación cognoscitiva, afectiva, social y axiológica-ética.

Puntualmente concluíamos que debemos trabajar con los niños y adolescentes entre muchas cosas, a manejar la informática y los mecanismos tecnológicos de manera positiva, a prevenir que existan conductas adictivas hacia los medios, a respetar al prójimo y a la 
naturaleza, a evitar conductas antisociales, la contaminación del ambiente, entre otros problemas psicosociales.

Finalmente, en palabras de León y Zambrano hoy vivimos "Una atmósfera de sordo desasosiego, de decepción y tristeza, que se filtra de modo indetenible por los resquicios del avance tecnológico y por la puerta grande del tiempo libre, matiza el horizonte espiritual del hombre de esta época" (León y Zambrano, 2008, p. 22). Es este inmenso poder de destrucción el que obliga a renovar y a expandir los principios éticos. Pero no se trata de que el bien máximo a preservar sea solo la vida humana, sino que ésta debe ser preservada para garantizar la supervivencia de la humanidad presente y de las generaciones humanas futuras sobre la Tierra (ob. cit. p. 9) así como la vida animal y vegetal en su conjunto. No tenemos el derecho de destruir nuestro sistema por una mayor comodidad momentánea, reducida y egoísta, además de inmoral es estúpido. Y eso debe estar claro.

\section{CONCLUSIONES}

Hans Jonas propone una nueva ética que pretende responder a esos retos que la actual civilización tiene planteados. Su texto, El principio de responsabilidad: Ensayo de una ética para la civilización tecnológica, fue publicada en Alemania a finales de la década de los setenta, lugar en el cual había eclosionado precisamente la conciencia ecológica.

Para nuestro autor la alta tecnología con la que contamos desde la segunda mitad de siglo XX, nos lleva a una urgente nueva praxis ética, que sin embargo choca con el vacío y la confusión producida por el relativismo exagerado de la actualidad. Y señala que no solo se trata de la supervivencia física del hombre sino de la integridad de su esencia.

En palabras de Restrepo: "La ética de la responsabilidad planteada por Hans Jonas responde a las demandas tecnocientíficas actuales a través de un nuevo imperativo axiológico" (Restrepo, 2011 ). Este imperativo, en el estilo kantiano, pero en el modo de Jonas sería: "Actúa de tal modo que los efectos de tu acción sean compatibles con la permanencia de una vida humana auténtica", o expresándolo de modo negativo: "No pongas en peligro la continuidad indefinida de la humanidad en la Tierra".

El valor es un concepto más subjetivo y el principio es más objetivo y normativo. Un principio es algo más regulador de la conducta, quizá por eso Jonas habla del principio de la responsabilidad más que del valor de la responsabilidad.

Vivimos décadas de la llamada obsolescencia programada, la política económica de programar el fin de vida útil de un producto mucho antes de lo que debería durar por supuesto, con el propósito de motivar a los consumidores a volver a comprar un nuevo número de ese producto una vez que el anterior haya fallado, pues o no hay forma de repararlo o no se venden repuestos, o éstos son tan o más caros que comprar un nuevo producto. Esto contribuye a un estilo de vida que perjudica también el ecosistema.

Pensemos en las consecuencias de nuestras acciones y en la sostenibilidad del ambiente. Las acciones humanas deben hacer sostenible a la naturaleza para que las siguientes generaciones puedan disfrutar de la vida. De manera responsable, consciente y moderada. En el trabajo de Jonas hay pues una reflexión sobre la relación hombre-naturaleza y la relación técnica-ciencia. 
Temas propios de la bioética y de la tecnoética deben considerarse en escuelas y universidades para ir entrenando el juicio crítico de las nuevas generaciones sobre nuestra responsabilidad con el ambiente. Y los padres desde casa deberían ser los primeros que inyecten el espíritu cuidadoso y respetuoso por la vida humana y animal, así como por el empleo oportuno y ético de una tecnología que ya empieza a desbordar todos los rincones del quehacer social.

A estar atentos para que los medios, la publicidad, las modas, el llamado neruomarketing y todas esas propagandas ("todo ilimitado"), con esos colores, esas melodías y esa publicidad chistosa que nos promete la felicidad al instante con solo comprar algo (que será luego desechado e intercambiado por otro igual), no se apropie de nuestra capacidad reflexiva, intencionalidad y libertad.

Concluimos con nuestro autor, Hans Jonas, que el ser humano requiere dar una respuesta válida y posible a una noción más amplia y radical de la responsabilidad, la referente a la naturaleza humana y extrahumana (animal y vegetal), ya que la tecnología moderna permite acciones transformadoras en un espectro enorme que va desde la manipulación del genoma humano hasta el plan de colonización espacial (de Siqueir, 2001).

\section{REFERENCIAS BIBLIOGRÁFICAS}

Arboccó de los Heros, M. (2019). La postmodernidad: sus tragedias y la esperanza en el ser humano. En Alternativas Cubanas en Psicología. Volumen 8, número 22.

Arboccó de los Heros, M. (2017). La obsolescencia programada. Publicado en el Diario Oficial El
Peruano. 13 de junio. https:// el peruano.pe/noticia-laobsolescencia-programada-56674. aspx

Arboccó de los Heros, M. (2016). El homo ciber. Publicado en el Diario Oficial El Peruano. 1 de diciembre. http://www.elperuano.pe/noticiael-homo-ciber-48906.aspx

Bakewell, S. (2015). En el café de los existencialistas. Ariel.

Bauman, Z. (2007). Vida de consumo. Fondo de Cultura Económica.

Beltrán, A. y Seinfeld, J. (2012). La trampa educativa en el Perú. Cuando la educación llega a muchos, pero sirve a pocos. Universidad del Pacífico.

de Siqueira, J.E. (2001). El Principio de Responsabilidad de Hans Jonas. En Acta Bioethica, 2001; año VII, nº 2.

de Siqueira, J.E. (2009). El Principio de Responsabilidad de Hans Jonas. En Revista Bioethikos del Centro Universitário São Camilo; 3(2):171 193.

Fromm, E. (2016). El Corazón del hombre. Fondo de Cultura Económica.

García, C. (2006). Cita a ciegas Sobre la imprevisibilidad de la vida. Reflexiones a partir de la obra Sincronización en Birkenwald, de Viktor Emil Frankl. San Pablo.

Gonzáles, G. (2015). El principio de responsabilidad de Hans Jonas a la luz de la conciencia ecológica. En Nómadas: Revista Crítica de Ciencias Sociales y Jurídicas. 
Jonas, H. (1995). El principio de la responsabilidad: Ensayo de una ética para la civilización tecnológica. Herder.

Lezama, J. (2007). Responsabilidad y tecnología según Hans Jonas. En Apuntes filosóficos. 30. 179 . 206 Universidad Católica Andrés Bellohttps://www. academia. edu/3437882/Responsabilidad_y_ tecnolog\%C3\%ADa_seg\%C3\%BAn_ Hans_Jonas

Onfray, M. (2005). Antimanual de Filosofía. EDAF.

Restrepo, J.C. (201 1). La teoría de la responsabilidad como imperativo ético. Hans Jonas y el principio axiológico para la tecnociencia. En Escritos: Vol. 19, N. 42 / pp. 079-121 enero-junio/ ISSN 0120 - 1263.
Savater, F. (2007). Las preguntas de la vida. Editorial Ariel.

\section{Fuentes de consulta adicionales}

:

Díaz Sánchez, José María (2015). Hans Jonas. El principio de responsabilidad. BLOG DE WORDPRESS.COM

https://hansjonasyelprincipio deresponsabilidad.word press. com/bibliografia/

Echevarría, Javier. (2003). El principio de responsabilidad: Ensayo de una axiología para la tecnociencia. Revista de filosofía moral y política. Isegoria. $\mathrm{N}^{\circ} 29$. 1 - 13. http://isegoria.revistas.csic. es/index.

php/isegoria/article/view/493

Fecha de recepción: 19/05/2021

Fecha de aceptación: 28/05/2021 